\title{
Modeling the coseismic groundwater level increase in the Oi well, central Japan
}

\author{
Yang $\mathrm{Li}^{1,3^{*}}$, Kazuhiro Itadera ${ }^{2}$, Masatake Harada ${ }^{2}$ and Motoo Ukawa ${ }^{3}$
}

\begin{abstract}
A model for coseismic groundwater level increase is presented for understanding hydrological responses of wells to seismic waves. Three types of coseismic groundwater level changes were observed in six wells $300-500 \mathrm{~m}$ in depth, operated by the Hot Spring Research Institute of Kanagawa Prefecture, central Japan. The first change was a sustained increase uniquely appearing at the Oi well. The second, a sustained decrease observed at most wells following the 2011 off the Pacific Coast of Tohoku Earthquake, and the third was an oscillatory response appearing in all six wells. In this study, we focused on the first response at the Oi well. We analyzed digital data at 1-Hz sampling rate of 12 events including shallow and deep earthquakes, and local to remote earthquakes from 2011 to 2016. There were 11 earthquakes which generated a sustained increase in the groundwater level in the Oi well from 5 to $10 \mathrm{~cm}$. The time series of the sustained increase in the Oi well was well approximated by the decaying exponential function, characterized by a time constant ranging from 156 to $363 \mathrm{~s}$. The slug test model for radial flow adequately represents the time curves observed in the Oi well, for which possible values of specific storage and hydraulic conductivity were used. The success of the application of the slug test model indicates a sudden increase in pore-pressure in the aquifer surrounding the well during the passage of seismic waves. We examined several candidates for the cause of the earthquake-triggered pore-pressure increase around the Oi well. We found that the poroelastic static strain change due to earthquake is not suitable for the sustained groundwater level increase at the Oi well. Qualitative examination suggests that following three models possibly explain the observed buildup times at the Oi well, but that all of them are not definitive: (a) permeability change due to barrier removal on the fracture surface, (b) undrained consolidation, and (c) gas bubble nucleation and growth.
\end{abstract}

Keywords: Coseismic groundwater level changes, Pore-pressure increase, Decaying exponential function, Radial flow slug test model

\section{Introduction}

Coseismic groundwater level change in wells has been observed throughout the world (e.g., Roeloffs 1998; Brodsky et al. 2003; Shi et al. 2013; Wang and Manga 2014; Kinoshita et al. 2015). The phenomenon has long been a focus in hydrology and seismology, because responses of groundwater in wells are related to various geophysical parameters, for example, the physical properties

\footnotetext{
*Correspondence: 5211082riyou@gmail.com

${ }^{1}$ Advanced Industrial Science and Technology, Earthquake and Volcano

Geology, Central 7, Higashi 1-1-1, Tsukuba, Ibaraki 305-8567, Japan

Full list of author information is available at the end of the article
}

of aquifer layers and surrounding rocks. Responses of groundwater are also related to tectonic deformation, earthquake precursors, induced seismicity and water supply variation (Wang and Manga 2010).

The observed groundwater level changes can be classified into two groups: oscillatory changes and sustained changes. The oscillatory changes correspond to seismic waves and period of oscillation typically ranges from 15 to $30 \mathrm{~s}$ (Cooper et al. 1965; Liu et al. 1989). Models of groundwater level oscillation resulting from seismic waves have been developed based on well-aquifer responses under pore-pressure oscillation during the 
passage of seismic waves (Cooper et al. 1965; Liu et al. 1989; Wang et al. 2009).

Sustained changes begin with a step-like increase or decrease with a buildup time ranging from several tenths of seconds to weeks and in some cases, they show gradual recovery after an exponential increase or decrease (Roeloffs 1998; Brodsky et al. 2003; Matsumoto and Roeloffs 2003; Wang and Manga 2014; Lai et al. 2016). Sustained groundwater level responses were first intensively identified by Roeloffs et al. (1995) and Roeloffs (1998), who analyzed observations in a well in California and demonstrated earthquake-enhanced permeability as a possible mechanism for the sustained increase in the groundwater level with gradual recovery. Three major mechanism categories have been proposed for the variety of hydrologic responses; poroelastic static strain, undrained consolidation, and earthquake-enhanced permeability (e.g., Wang and Manga 2014). These three mechanisms are not independent, and typically occur together. As it is difficult to directly observe changes to the aquifer status that changes during passage of seismic waves, the mechanism of the sustained response remains unclear.

In this study, we examined groundwater level changes observed by a groundwater level observational network composed of six wells operated by the Hot Springs Research Institute of Kanagawa Prefecture (HSRI). Among them, we focused on the Oi well, which showed a sustained groundwater level increase responding to seismic waves. The groundwater level observational network provides high-quality digital data recorded at a high sampling rate of $1 \mathrm{~Hz}$. Using the data set, we attempted to build a model to explain the sustained groundwater level response in the Oi well.

\section{Well setting and data \\ Observation wells}

The groundwater level observational network was established by the HSRI to study the relation between earthquakes and groundwater level changes in the western part of Kanagawa Prefecture, central Japan. The observational network consists of six wells, completed in March 1994 (Yokoyama et al. 1995). The observational network area is close to the Sagami trough and the Kozu-Matsuda fault, which are along the plate boundary between the North American and Philippine Sea plates (Fig. 1).

Table 1 summarizes the well geometrical and hydrological properties. The well depths range from 300 to $500 \mathrm{~m}$ and the range of hydraulic conductivity for the screened layer at the bottom of wells is from $10^{-4}$ to $10^{-8} \mathrm{~m} / \mathrm{s}$. Barometric effects on the groundwater level vary from 1.1 to $8.9 \mathrm{~mm} / \mathrm{hPa}$.

The groundwater level is measured using a pressure type water level sensor with $1 \mathrm{~mm}$ precision. Groundwater level data has been digitally recorded at a $1-\mathrm{Hz}$ sampling rate since September 2010. In this study, we used digital data collected from January 2011 to April 2016.

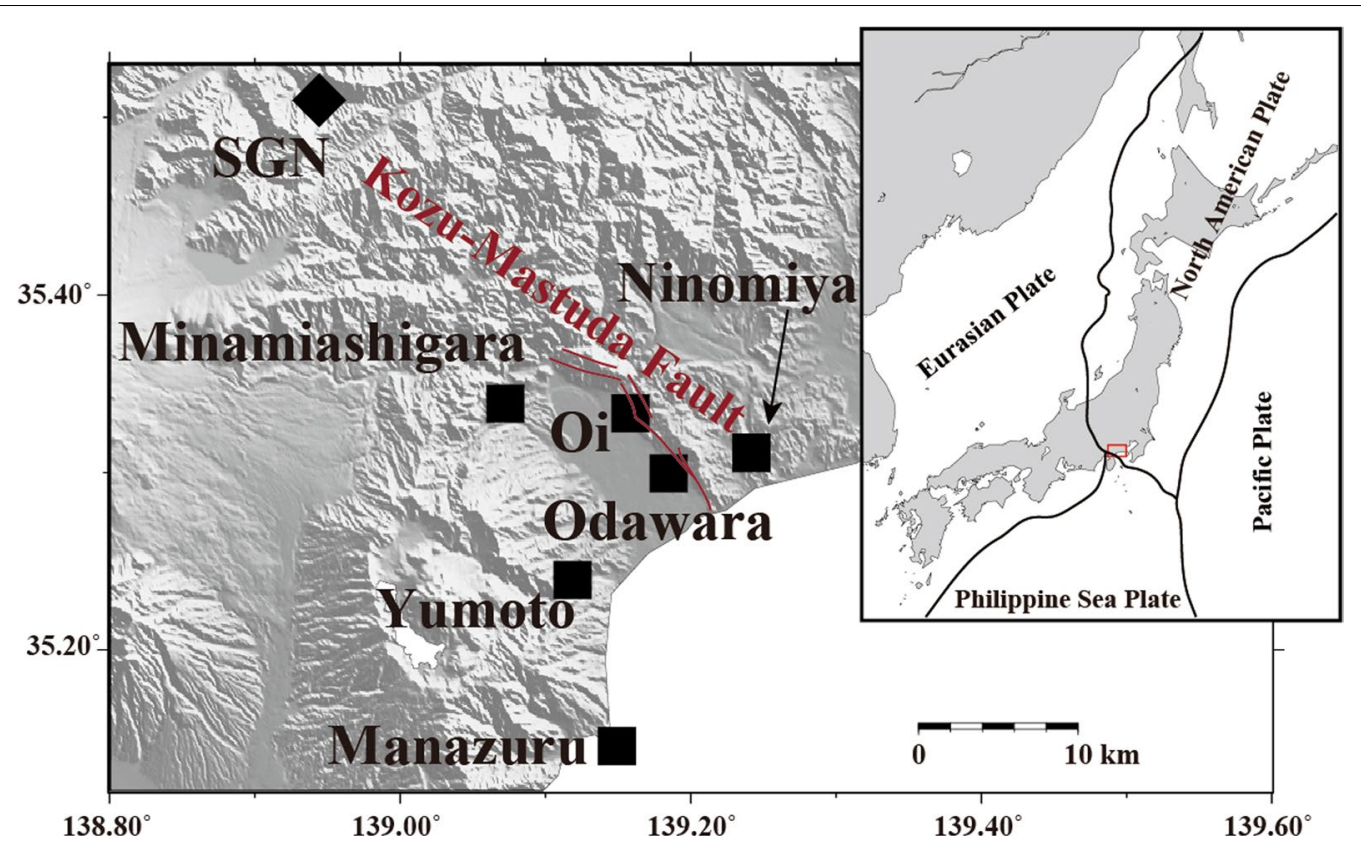

Fig. 1 Map showing the observation wells of the HSRI. Squares indicate the locations of the wells by the HSRI. A diamond shows the F-net station, SGN. Red lines indicate the surface traces of the Kozu-Matsuda fault (Yamazaki 1993). Plate boundaries are indicated by thin lines in the map on the right-hand side 
Table 1 Well parameters

\begin{tabular}{lllllll}
\hline Parameter & Oi & Odawara & Minamiashigara & Yumoto & Manazuru & Ninomiya \\
\hline Depth $(\mathrm{m})^{*}$ & 300 & 300 & 150 & 300 & 300 & 500 \\
Screen depth $(\mathrm{m})^{*}$ & $270-300$ & $270-300$ & $120-150$ & $250-300$ & $250-300$ & $450-500$ \\
Hydraulic conductivity $(\mathrm{m} / \mathrm{s})^{*}$ & $5.5 \times 10^{-6}$ & $1.4 \times 10^{-4}$ & $8.7 \times 10^{-6}$ & $1.7 \times 10^{-8}$ & - & $-6.1 \times 10^{-8}$ \\
Borehole radius $(\mathrm{m})^{* *}$ & 0.05265 & 0.05265 & 0.05265 & - & - & - \\
Screen radius $(\mathrm{m})^{* *}$ & 0.03395 & 0.03395 & 0.03395 & - & - & - \\
Barometric efficiency $(\mathrm{m} / \mathrm{hPa})^{* * *}$ & 0.0039 & 0.0047 & 0.0047 & 0.0011 & 0.0089 & 0.0054 \\
\hline
\end{tabular}

*Referred to Yokoyama et al (1995)

**Referred to unpublished data from well construction report

***Referred to to Itadera (2003)

There were no data available for 1 week after the 2011 off the Pacific Coast of Tohoku Earthquake of Mw 9.1 because of clock malfunctions.

In addition to the groundwater level data, we used seismograms observed at the closest broadband seismometer station SGN (Turusugeno) belonging to F-net operated by the National Research Institute for Earth Science and Disaster Resilience (2019). The station (SGN) is approximately $25 \mathrm{~km}$ northwest of the HSRI groundwater observational network (Fig. 1). The seismogram data are provided in digital form at a $100 \mathrm{~Hz}$ sampling rate. The response of the broadband seismometers of the F-net stations was flat within a frequency range from 0.01 to $20 \mathrm{~Hz}$ (Okada et al. 2004).

\section{Groundwater level changes}

Both oscillatory and sustained groundwater level changes were observed in the six wells in association with large earthquakes. Among them the Oi well had a consistent sustained increase, except for the case of the 2011 earthquake off the Pacific Coast of Tohoku, after which the groundwater level decreased by $25 \mathrm{~cm}$. Typical examples of the groundwater level changes are shown in Fig. 2. Figure $2 \mathrm{a}-\mathrm{d}$ show the changes in the six wells responding to the shallow Mw 6.4 earthquake (focal depth: $9 \mathrm{~km}$ ) with an epicentral distance (from the Oi well) of $185 \mathrm{~km}$, the deep Mw 6.5 earthquake (focal depth: $402 \mathrm{~km}$ ) with an epicentral distance of $601 \mathrm{~km}$; the distant shallow Mw 7.8 earthquake (focal depth: $8 \mathrm{~km}$ ) with an epicentral distance of $5141 \mathrm{~km}$; and the Mw 9.1 great earthquake (focal depth: $29 \mathrm{~km}$ ) with an epicentral distance of $436 \mathrm{~km}$, which is the 2011 earthquake off the Pacific Coast of Tohoku, respectively. The distances to the Oi well, depths, and magnitudes of the earthquakes shown in Fig. 2 are listed in Table 2. The seismograms of the vertical, radial, and transverse components observed at the SGN station are shown at the bottom of each figure.

The groundwater level changes shown in Fig. 2a were the most commonly observed pattern, where oscillatory changes appeared at all wells. Among them, the Odawara well had the largest amplitude with a maximum half amplitude of $1.8 \mathrm{~cm}$, and those of the other five wells including Oi well range from 0.3 to $0.8 \mathrm{~cm}$. In the case of the Oi well, the oscillatory change with the maximum half amplitude of $0.6 \mathrm{~cm}$ was superposed on the sustained increase. This pattern of groundwater level change was observed not only for shallow earthquakes (Fig. 2a) but also for deep earthquakes (Fig. 2b), and distant earthquakes (Fig. 2c).

Comparing the groundwater level changes to the seismograms at SGN shown in the figures, the groundwater level oscillations start as the seismic wave arrives, and continue during the seismic waves oscillatory intervals. In contrast, the sustained groundwater level changes in the Oi well seem to start with the arrivals of the relatively large amplitude seismic waves, as shown in Fig. 2c.

Figure $2 \mathrm{~d}$ shows that oscillatory changes and a sustained groundwater level decrease clearly appeared in the three wells at Ninomiya, Minamiashigara and Oi in response to the main shock (Mw 9.1) of the 2011 earthquake off the Pacific Coast of Tohoku and the largest aftershock (Mw 7.9) of the event, which occurred $29 \mathrm{~min}$ after the main shock. The observed maximum amplitude of the oscillatory groundwater level changes was 10 times greater than those of the other events. For example, the maximum half amplitude of the Odawara well exceeds $1 \mathrm{~m}$. The large amplitudes of the oscillatory changes were caused by the large seismic wave amplitudes. This event was a unique earthquake that caused a sustained groundwater level decrease in the HSRI groundwater observational network. This decrease presumably occurred because of the extremely large static extensional areal strain produced by the earthquake fault dislocations in the near-field distances. Areal strain of approximately 1 micro-strain was observed around the western part of the Kanagawa prefecture (Ohzono et al. 2012). The groundwater level decreases during this earthquake are also reported by Niwa et al. (2012) and Kinoshita et al. (2015) 
Li et al. Earth, Planets and Space

(2021) $73: 168$

Page 4 of 20

a
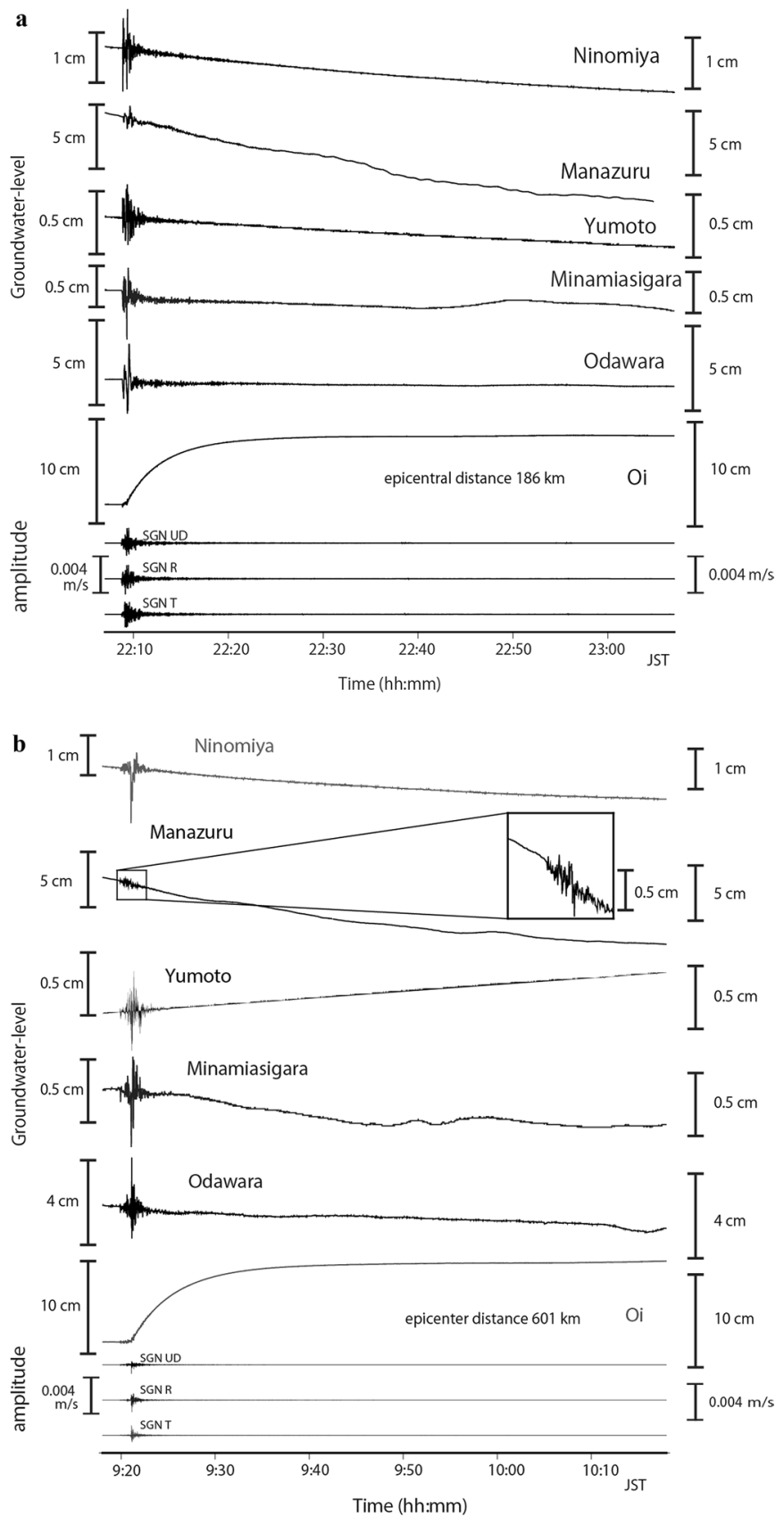

Fig. 2 Groundwater level changes in the six wells of the HSRI observational network for four earthquakes. a Responses to the M6.2 earthquake of November 22, 2014, in the northern Nagano prefecture, central Japan (event 9 in Table 2). The epicentral distance range is from 184 to $201 \mathrm{~km}$. b Responses to the M6.5 earthquake of September 4, 2013, in the lIz Benin region, southern Japan (event 4 in Table 2). The epicentral distance range is from 579 to $601 \mathrm{~km}$. c Response to the M7.8 earthquake of April 25, 2015 (event $10 \mathrm{in}$ Table 2). The epicentral distance range is from 5133 to $5148 \mathrm{~km}$. The vertical line indicates the arrival time of Rayleigh waves identified on the seismogram. The propagation velocity is approximately $3.25 \mathrm{~km} / \mathrm{s}$, which is in agreement with the group velocities of Rayleigh waves with oscillation period of $30 \mathrm{~s}$ along the propagation path in and around China (Fens and An 2010). d Response to the M9.1 earthquake of March 11, 2011 near the east coast of Honshu, Japan (event 1 in Table 2). The epicentral distance range is from 433 to $453 \mathrm{~km}$ 


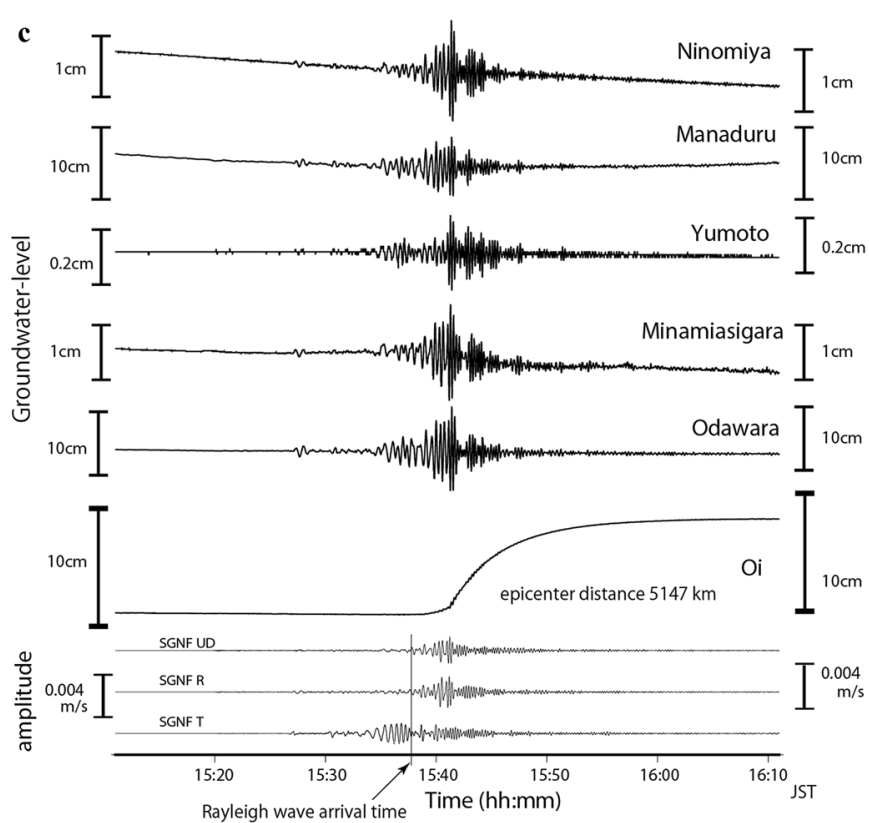

d
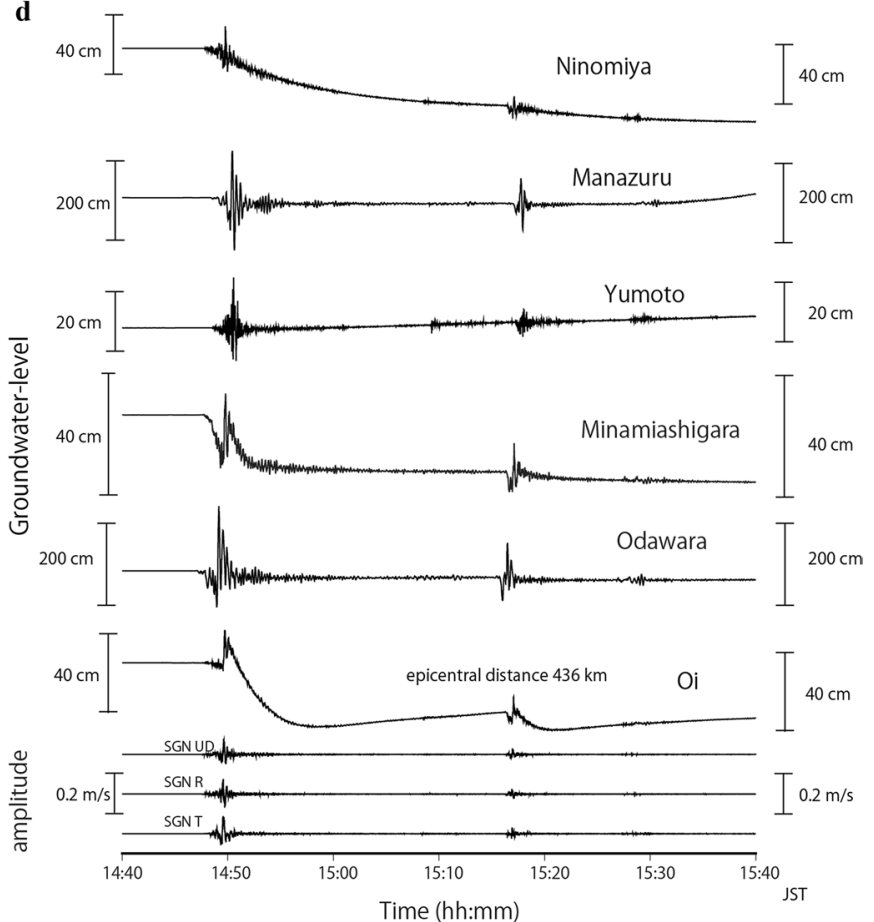

Fig. 2 continued

in central Japan. Kitagawa and Koizumi (2011) report the groundwater level changes in western Japan due to this event.

The dominant response of groundwater level to earthquakes in the Oi well is a sustained increase and in the other five wells it is typically an oscillatory response.
The dataset of the HSRI groundwater level observational network provides a great opportunity to investigate sustained groundwater level change using high-quality data with broadband seismic data at a station of F-net within a proximal distance. In this study, we focused on the 


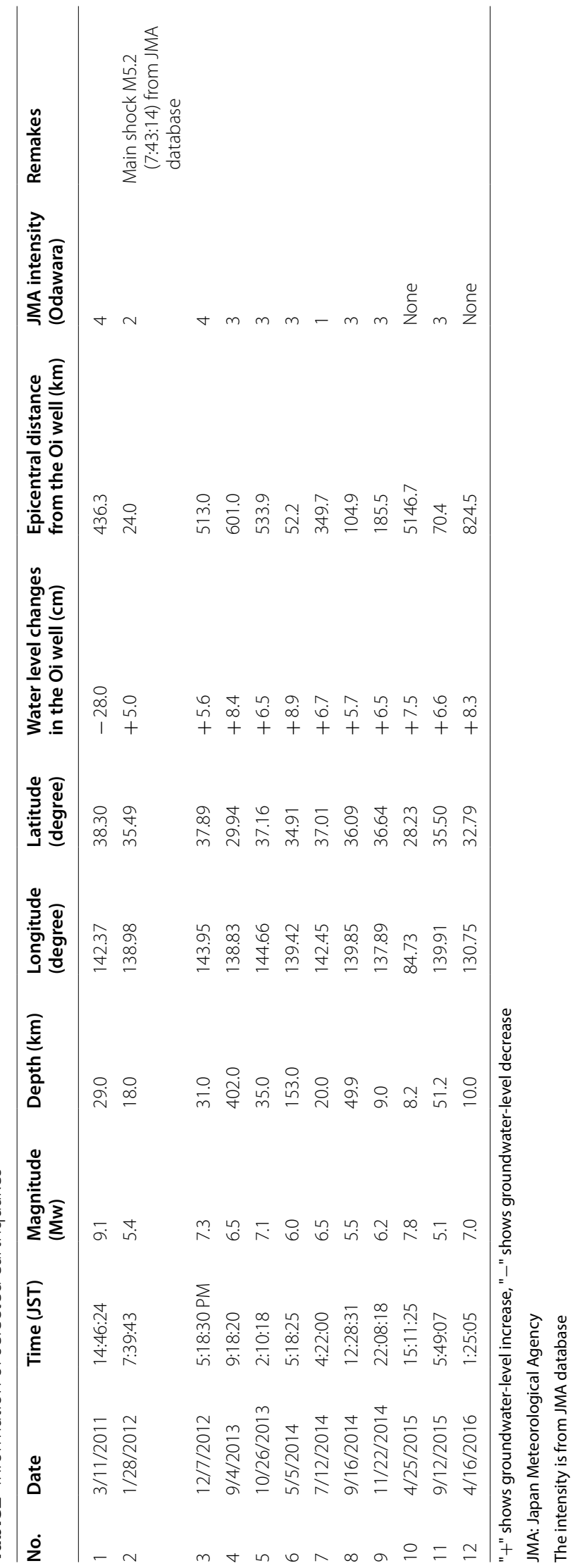


sustained groundwater level increase observed in the Oi well.

\section{Analyzed events}

We chose earthquake events that caused sustained groundwater level change in the Oi well from January 2011 to April 2016. To reduce the number of events to be examined in digital form, we first determined a minimum magnitude-epicentral distance relation from data during 2012. Based on this relation, we set a reference line to examine groundwater level changes for other periods. The procedure was as follows:

(1) We examined groundwater level changes observed in the Oi well in association with earthquakes with magnitude larger than Mw 6 during 2012 and discriminated earthquakes causing groundwater level changes in the Oi well.

(2) We plotted the extracted earthquakes on a magnitude-epicentral distance graph (semi-logarithmic plot) and then determined the straight line that expresses a minimum magnitude-distance relation, $M_{\min }(\Delta)$, where $\Delta$ is the epicentral distance, by connecting the minimum magnitude at various epicentral distances. The obtained minimum magnitude-epicentral distance relation is $M_{\min }(\Delta)=1.58 \log \Delta+1.93$ (Fig. 3a).

(3) We checked the groundwater level changes for earthquakes during the period from 2011 to 2016, including earthquakes smaller than Mw 6 for 2012. To pick up all the events which cause the groundwater level change at Oi well, we set a reference line. The events above this line are the events that we need to check the digital data. In the present study, the reference line is set to be $M_{\text {min }}(\Delta)-1$, which means the reference line is $M_{\min }(\Delta)=1.58 \log \Delta+0.93$. Within the epicentral distance range where $M_{\min }(\Delta)$ is less than 4.5, we set $M_{\min }(\Delta)=4.5$ (Fig. 3a). As shown in Fig. 3a, there is no target event between the reference line and the minimum magnitude-epicentral distance

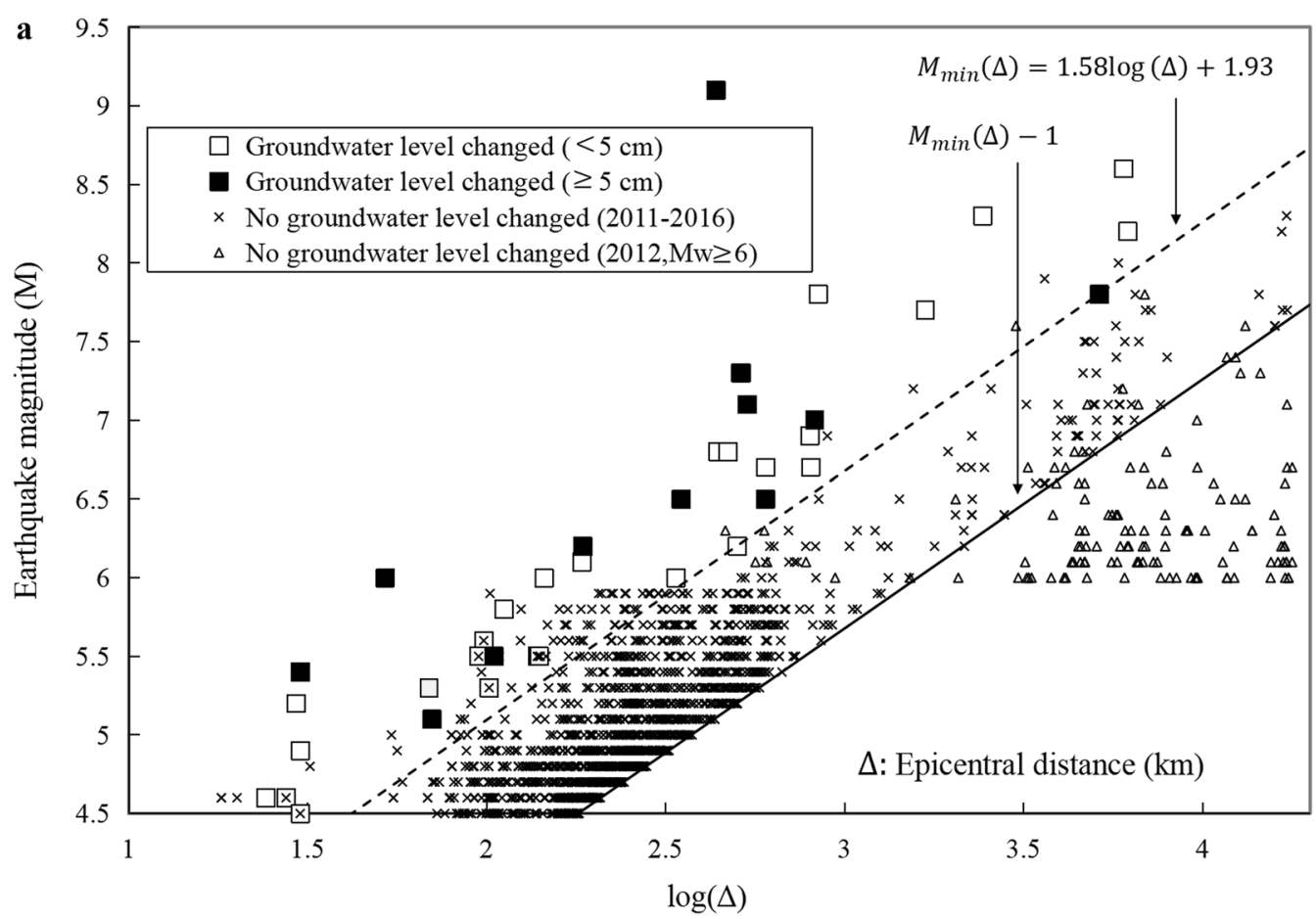

Fig. 3 Epicenters of the analyzed events and the examined events. a The magnitude-epicentral distance relation of groundwater level change in the Oi well. The broken line is the referenced magnitude-epicentral distance line which indicates the minimum magnitude for the groundwater level change in Oi well in 2012. The straight line is the basic line, for earthquakes above which we checked the groundwater level in the Oi well from 2011 to 2016. The solid and open squares show the events which caused the groundwater level changes larger than or equal to $5 \mathrm{~cm}$ in the Oi well and those less than $5 \mathrm{~cm}$, respectively. The open triangles show the events ( $M w \geq 6$ ) in 2012, which we examined and found no groundwater level change in the Oi well. The crosses show the events, which we examined and found no groundwater level change in the Oi well for the period from 2011 to 2016. b The circles indicate the epicenters of the analyzed events. The number in the circle indicates the event number in Table 2 . The plus marks show the events from 2011 to 2016, which accompany no groundwater level change or the groundwater level change less than $5 \mathrm{~cm}$. The top figure shows the global map, and the bottom figure shows the area around Japan 


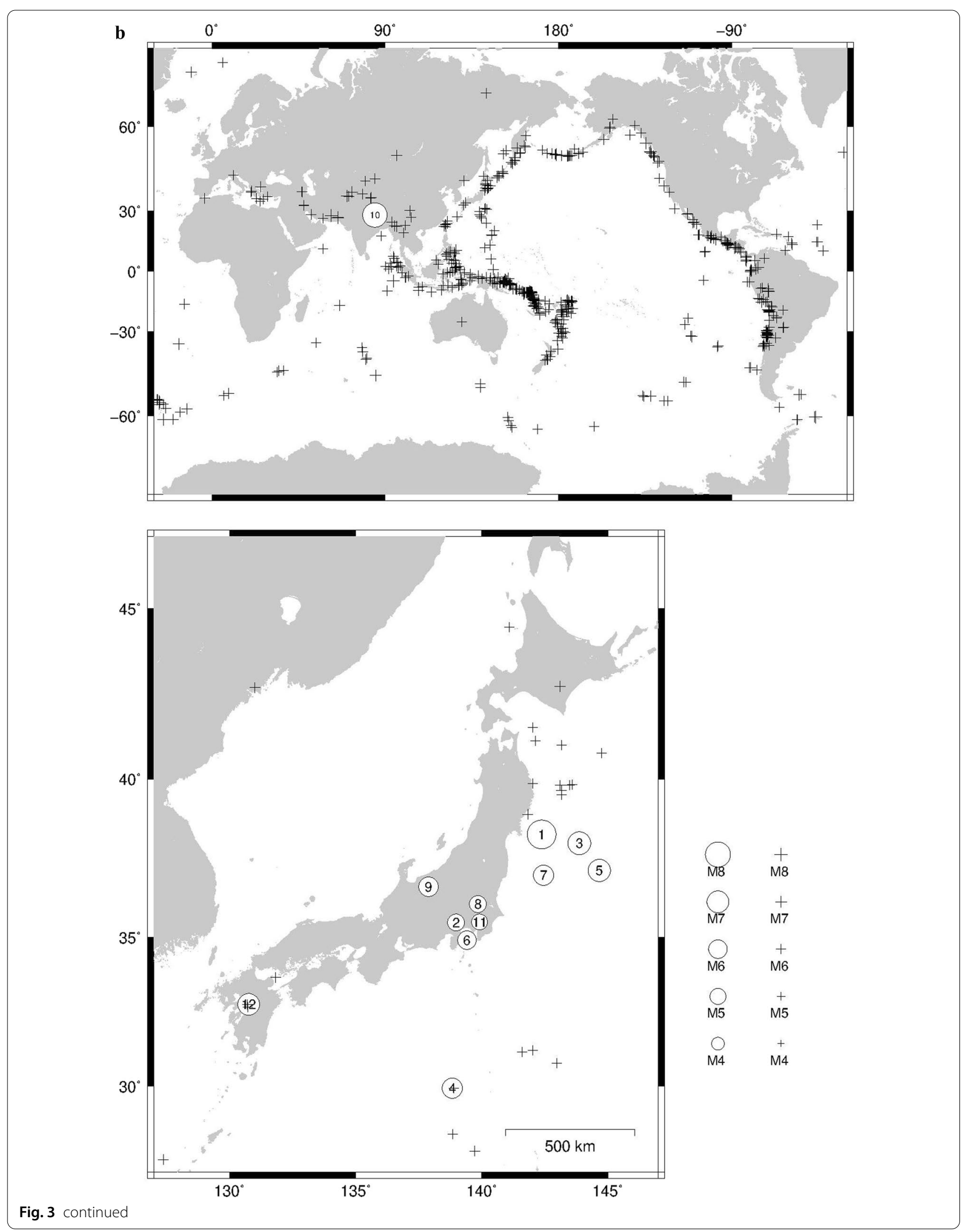


relation in step (2), indicating that the reference line covers all the target events.

(4) We extracted the events which accompanied a groundwater level change greater than or equal to $5 \mathrm{~cm}$ in the Oi well.

For the hypocenter parameters, the Preliminary Determination of Epicenter (PDE) data by the U.S. Geological Survey (USGS) were used. Figure 3a presents the magnitude-distance relation, showing the earthquakes examined and two equations mentioned above. After checking the groundwater level data of 1586 events via the aforementioned procedure, a total of 12 events which produced groundwater level changes greater than or equal to $5 \mathrm{~cm}$ were extracted for modeling study. The hypocenter parameters of the selected 12 events are listed in Table 2 and the epicenters are plotted in Fig. 3b. For event 2, the hypocenter parameters by Japan Meteorological Agency (JMA) were used, because the focal depth of event 2 by the PDE is too deep for this region. Figure $3 \mathrm{~b}$ also shows events which produced no change or groundwater level changes less than $5 \mathrm{~cm}$ in the Oi well. The most distant earthquake was the 2015 Nepal earthquake (Mw 7.8) with an epicentral distance of $5141 \mathrm{~km}$. The closest earthquake was the Mw 5.4 earthquake on January 28, 2012, with an epicentral distance of $24 \mathrm{~km}$. This event followed the Mw 4.9 foreshock which occurred 5 min before the main shock.

\section{Groundwater level response in the Oi well Characteristics of the groundwater level response in the $\mathrm{Oi}$ well}

Responding to the selected 12 earthquakes, the Oi well showed very similar groundwater level changes of a sustained increase except for event 1 (the 2011 earthquake off the Pacific Coast of Tohoku). Figure 4 shows the groundwater level changes of the 11 earthquakes where the groundwater level increased in the Oi well.

In Fig. 4, all groundwater level data are plotted in the same time and amplitude scales by aligning the start times of groundwater level increase at the same horizontal position. In each trace, we plotted the $\mathrm{P}$ and $\mathrm{S}$ wave arrival times calculated by the TauP Toolkit (Crotwell et al. 1999) based on the Preliminary Reference Earth Model (PREM). The average with standard deviation of the $\mathrm{P}$ wave travel-time residuals at SGN calculated from the PREM and the hypocenters in Table 2 is $-1.2 \pm$ $1.5 \mathrm{~s}$, showing the PREM provides appropriate arrival times for the Oi well for the present study. This indicated that the groundwater level increases began almost simultaneously with $\mathrm{S}$ arrivals or after $\mathrm{S}$ arrivals. In the case of the 2015 Nepal earthquake, the groundwater level greatly

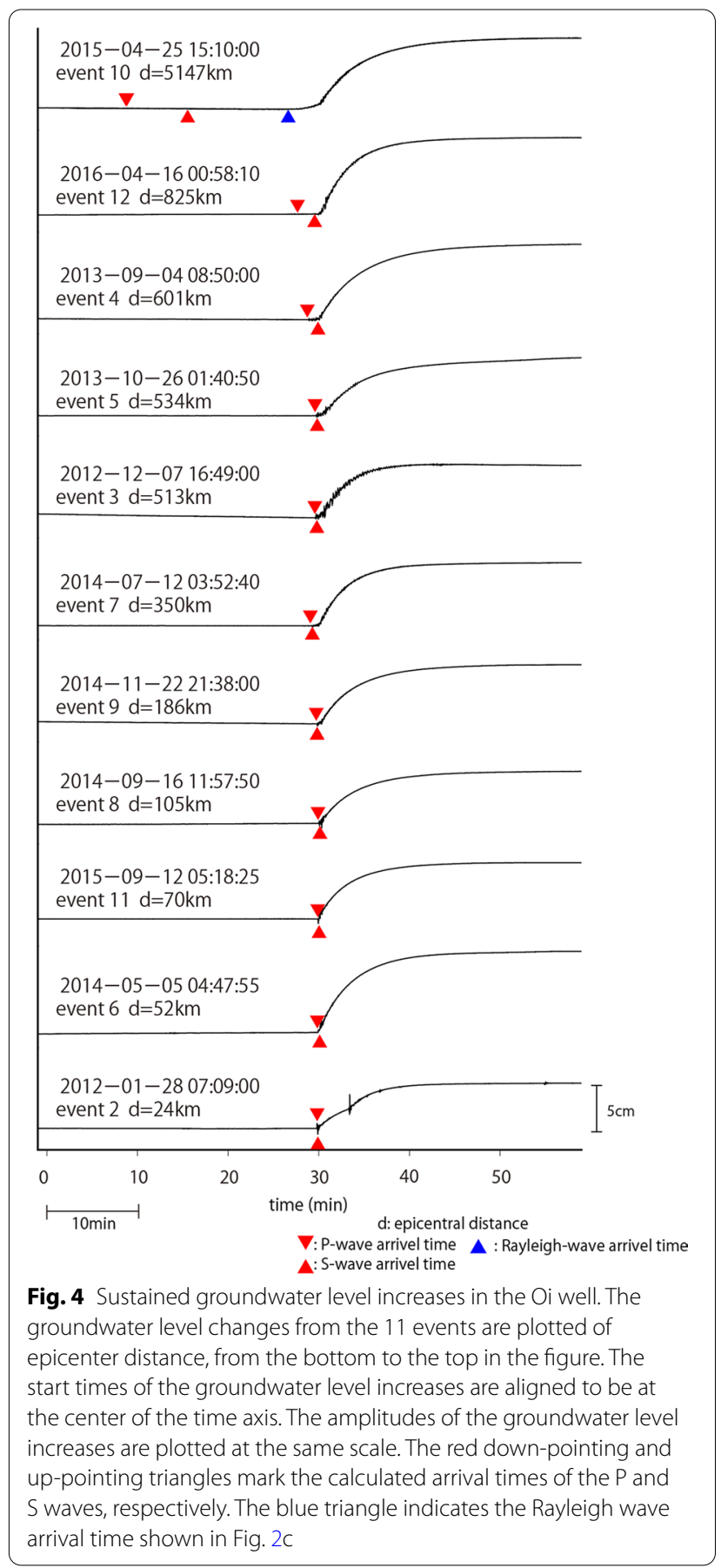

changed around the arrival of Rayleigh waves, which is indicated in Fig. 4.

Regarding with the seismic amplitude at the start of the sustained groundwater increase, the seismograms observed at SGN show that the start times of the sustained groundwater level increases correspond to times when seismic amplitudes exceeded approximately $1 \mathrm{~mm} / \mathrm{s}$ on any component seismograms for all events in 
Table 2. However, the start times correspond to different seismic phases, P, S, or Rayleigh waves, depending on the events. In some cases, groundwater level did not show any sustained change, even when the maximum amplitude at SGN exceeded $1 \mathrm{~mm} / \mathrm{s}$. It is certain that large amplitude seismic waves trigger the sustained groundwater level increases, but it is difficult to specify the threshold trigger level.

The maximum amplitudes of groundwater level increases ranged from 5 to $10 \mathrm{~cm}$, as summarized in Table 2. It is noticeable that the groundwater level changed in a similar manner with the same convex curvature. This means there was a decay of increase rate of the groundwater level with similar buildup times, probably related to the mechanism of the sustained response to the earthquake. To quantify these characteristics, we approximated observed time series data by a suitable function. To determine the function, we applied three functions typical in hydrology and fluid dynamics to the observations. The selected candidates for the time function were the decaying exponential, error, and logistic functions.

\section{Fitting curves}

The decaying exponential function has been applied in several previous studies (Roeloffs 1998; Kinoshita et al. 2015). In the case of the decaying exponential function, the groundwater level at time $t, H(t)$, can be expressed as follows:

$$
H(t)=a(1-\exp (-b t)) .
$$

The well function proposed by Theis (1952) had been applied to observed changes in the well head in several studies (Koizumi et al. 1996; Roeloffs 1998). The error function is commonly used as an approximate solution to the well function (Hantush 1964; Abramowitz and Stegun 1972). We chose the error function as a possible candidate for the suitable function. In this case, the groundwater level at time $t, H(t)$, is expressed as follows:

$$
H(t)=a \int_{0}^{t} \exp \left(-b x^{2}\right) d x .
$$

As the logistic function has been applied in fluid dynamics studies (Zhang et al. 2001), we also considered this function as a candidate. The logistic function is expressed as follows:

$$
H(t)=\frac{a}{c+e^{-b t}} .
$$

In Eqs. (1) and (2), the maximum amplitude is expressed by the parameter $a$. The time constant is expressed as $1 / b$, and represents the required time from the initial response to become $1 / e$ of the maximum amplitude. In Eq. (3), the parameter $c$ adjusts the increase rate, incorporating the time constant $b$, and the maximum amplitude is expressed as $a / c(c+1)$.

Prior to fitting, the barometric pressure effect on groundwater level was corrected using the barometric coefficient method, which was successfully applied to the Oi well (Itadera 2003). In this method we assume that groundwater level change is primarily affected by the barometric pressure, and that the effect of barometric pressure to the groundwater level is linear. The barometric coefficient is calculated from correlation coefficient between observed groundwater level and barometric pressure. Then we remove the barometric effect from observed groundwater level data.

We attempted to determine the best function among the three to approximate the observed sustained increase by applying the three functions to the groundwater level changes following the 11 events, except for event 1 . Figure $5 \mathrm{a}$ shows an example of groundwater level changes resulting from event 10 fitted by the three functions. The differences in the fitting curves and the observed data are plotted below the groundwater level curve in this figure. The parameter $a$ was calculated from the maximum change in the data. The parameters $b$ and $c$ were estimated using the grid search method, in which the starting time was also estimated by shifting the functions with a 1-s interval. The grid intervals for $b$ in Eq. (1) were $0.0001 \mathrm{~s}^{-1}$ that for $b$ in Eq. (2) was $0.0001 \mathrm{~s}^{-2}$, that for $b$ and $c$ in Eq. (3) were $0.001 \mathrm{~s}^{-1}$ and 0.01 , respectively. The best solution for each function was determined in the least squares sense for 60 -min interval data from the starting time.

We used Akaike's Information Criterion (AIC) to evaluate the likelihood of objectively fitting, calculated as follows:

\footnotetext{
(See figure on next page.)

Fig. 5 a Examples of the three fitting functions. This graph shows the fitting results using the three functions for event 11; the logistic function (top), error function (middle) and decaying exponential function (bottom). The solid line indicates the fitting curve overlapping on the observed data (one-dot chain line) for each function. The differences between the observed data and the fitting curve are plotted for each function. $\mathbf{b}$ Fitting results of the decaying exponential function for the 11 events. This graph shows the fitting curves of the decaying exponential function (solid line) and the observed data (the one-dot chain line) for the 11 earthquakes from event 2 to event 12 . The differences between the observed data and the fitting curves are plotted for each event. The amplitude of the groundwater level and fitting data are plotted at same scale for the all events
} 
$\mathbf{a}$

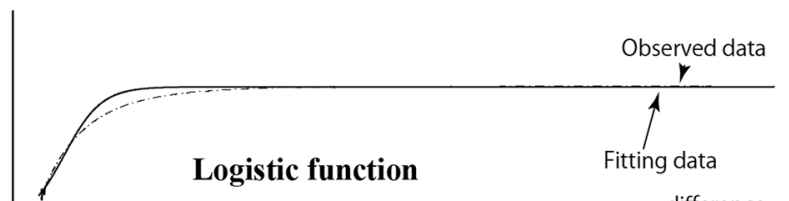

difference

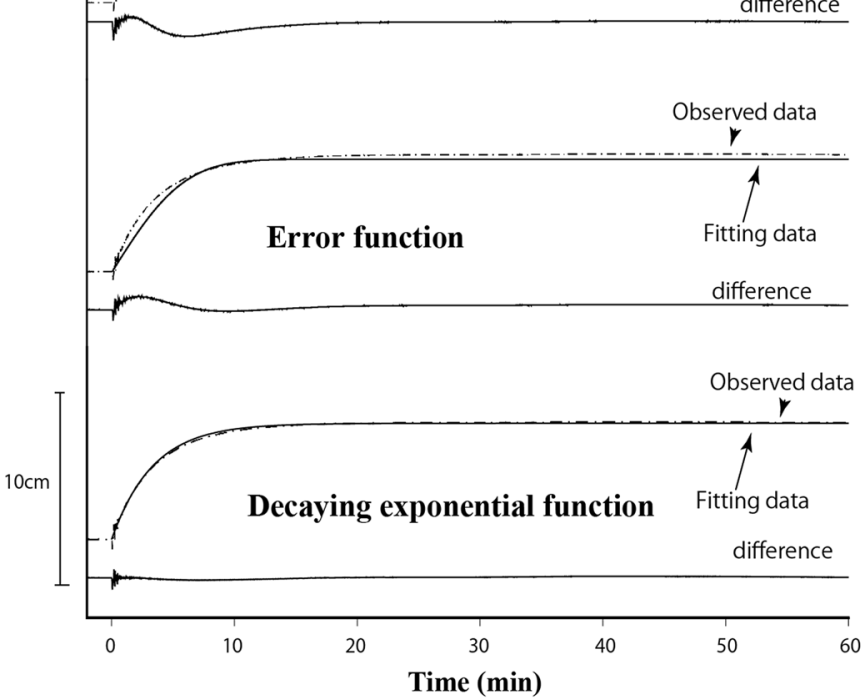

b

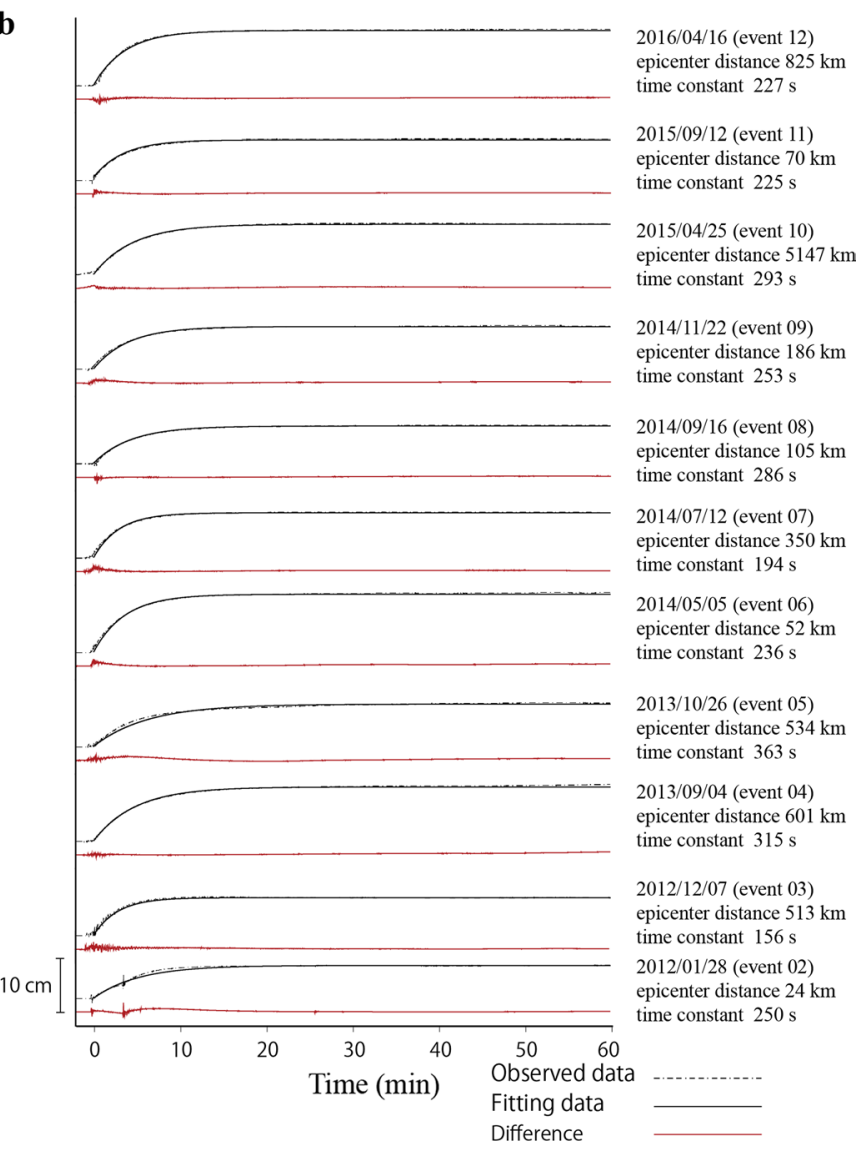

Fig. 5 (See legend on previous page.) 
Table 3 Result of fitting

\begin{tabular}{|c|c|c|c|c|c|c|c|c|c|c|c|c|c|}
\hline \multirow[t]{2}{*}{ No. } & \multirow[t]{2}{*}{ Date } & \multicolumn{4}{|c|}{ Decaying exponential function } & \multicolumn{4}{|c|}{ Error function } & \multicolumn{4}{|c|}{ Logistic function } \\
\hline & & $a$ & $b$ & $1 / b$ & AIC & $a$ & $b$ & $1 / b$ & AIC & $a$ & $b$ & c & AIC \\
\hline 2 & $1 / 28 / 2012$ & 0.049 & 0.0040 & 250 & -47386 & 0.049 & 0.0024 & 424.36 & -50584 & 0.057 & 0.009 & 0.97 & -45092 \\
\hline 3 & $12 / 7 / 2012$ & 0.057 & 0.0064 & 156 & -48794 & 0.055 & 0.0039 & 256 & -46836 & 0.065 & 0.016 & 0.98 & -42458 \\
\hline 4 & 9/4/2013 & 0.082 & 0.0032 & 315 & -47350 & 0.081 & 0.0020 & 510.76 & -41598 & 0.088 & 0.010 & 0.97 & -35920 \\
\hline 5 & $10 / 26 / 2013$ & 0.064 & 0.0028 & 363 & -43282 & 0.063 & 0.0018 & 556.96 & -40150 & 0.070 & 0.009 & 0.97 & -36253 \\
\hline 6 & $5 / 5 / 2014$ & 0.088 & 0.0042 & 236 & -44892 & 0.088 & 0.0025 & 400 & -40293 & 0.094 & 0.014 & 0.98 & -36087 \\
\hline 7 & $7 / 12 / 2014$ & 0.068 & 0.0052 & 194 & -46446 & 0.068 & 0.0031 & 324 & -42638 & 0.076 & 0.016 & 0.98 & -39240 \\
\hline 8 & $9 / 16 / 2014$ & 0.057 & 0.0035 & 286 & -49639 & 0.056 & 0.0022 & 457.96 & -44863 & 0.064 & 0.010 & 0.98 & -40020 \\
\hline 9 & $11 / 22 / 2014$ & 0.064 & 0.0040 & 253 & -46607 & 0.064 & 0.0024 & 416.16 & -42244 & 0.071 & 0.012 & 0.98 & -38195 \\
\hline 10 & $4 / 25 / 2015$ & 0.076 & 0.0034 & 293 & -49346 & 0.076 & 0.0020 & 492.84 & -42695 & 0.082 & 0.010 & 0.97 & -37067 \\
\hline 11 & $9 / 12 / 2015$ & 0.061 & 0.0044 & 225 & -48049 & 0.061 & 0.0027 & 376.36 & -43344 & 0.069 & 0.013 & 0.98 & -39651 \\
\hline 12 & $4 / 16 / 2016$ & 0.083 & 0.0044 & 227 & -48280 & 0.082 & 0.0027 & 368.64 & -43968 & 0.090 & 0.014 & 0.98 & -38369 \\
\hline
\end{tabular}

$$
\mathrm{AIC}=N \log \left(\sigma^{2}\right)+2 p,
$$

where $N$ is the number of fitting data; $\sigma$ is the residual between the observed and fitting data, and $p$ is the number of parameters in the fitting function (Akaike 1987). A smaller AIC value means it is more suitable for fitting.

The AIC results are listed in Table 3. For 10 of the 11 events, the AIC values of the decaying exponential function show the smallest value. For event 2, the error function has the smallest AIC value, being different from other events. This difference may be attributable to its two-step response to the $\mathrm{Mw} 4.9$ foreshock and $\mathrm{Mw} 5.4$ main shock as shown in Fig. 4. Among these three functions, the decaying exponential function was the best fitting function in terms of the AIC values for the sustained groundwater level increase in the Oi well. The parameter $b$, which is an inverse of the time constant, was within the range from 0.0028 to $0.0064 \mathrm{~s}^{-1}$, which corresponds to the time constant range from 156 to $363 \mathrm{~s}$. The average and standard deviation of the time constant were $254 \mathrm{~s}$ and $58 \mathrm{~s}$, respectively. The resulting decaying exponential function for the observed groundwater level changes following the 11 earthquakes are plotted with the observed data in Fig. 5b. Here, the decaying exponential functions nearly overlap on the observed time series, showing that the decaying exponential function was suitable for quantifying the sustained groundwater level increase in the Oi well. The time constants obtained showed no apparent dependence on the magnitudes of the earthquakes or intensities in Odawara city.

\section{Aquifer-well system model Slug test model}

In the previous section, we found that the time constants of the groundwater level increase are relatively short intervals of several minutes, much shorter than those reported by previous studies. Roeloffs (1998) reported 1.8 days for a 30-m-deep well in California. Koizumi and Kinoshita (2016) reported 30-60 days for wells from 195- to 300-m-deep in Japan. In Kühn and Schöne (2018), the time constant was approximately 15 days in a 400-m-deep well following the Kaikoura earthquake in New Zealand. In these studies, the groundwater levels of the well are assumed to be in equilibrium with the water head in the surrounding aquifer.

As the time constants of the sustained increase in the present study are quite short, within the range from 2 to $6 \mathrm{~min}$, we needed to examine the time constant of the wellaquifer system, that is the response to step-like change. The slug test was applied to examining the time constant of the well-aquifer system. The slug test is a method to measure aquifer permeability via a sudden insert or removal of a slug, causing a sudden water level change in the well. The theory of a non-oscillatory response with the solution was proposed by Cooper et al. (1967) and Papadopulos et al. (1973). Kipp (1985) presented the condition of underdamped and overdamped cases. The groundwater level change is overdamped when the dimensionless damping parameter is greater than 1.0. The groundwater level change in the Oi well was overdamped, because the dimensionless damping parameter calculated from the well parameters in Table 1 and the specific storage estimated in "Results" section was in the range from 3 to 5.

To examine the possibility of a sudden increase in porepressure in the near-well aquifer, we estimated the wellaquifer system time constant by applying the analytical method proposed by Karasaki et al. (1988), which addresses overdamped cases. Karasaki et al. (1988) considered two states of flow: linear and radial flow. Images of radial and linear flow are shown in Fig. $6 \mathrm{a}$ and b, respectively. The 


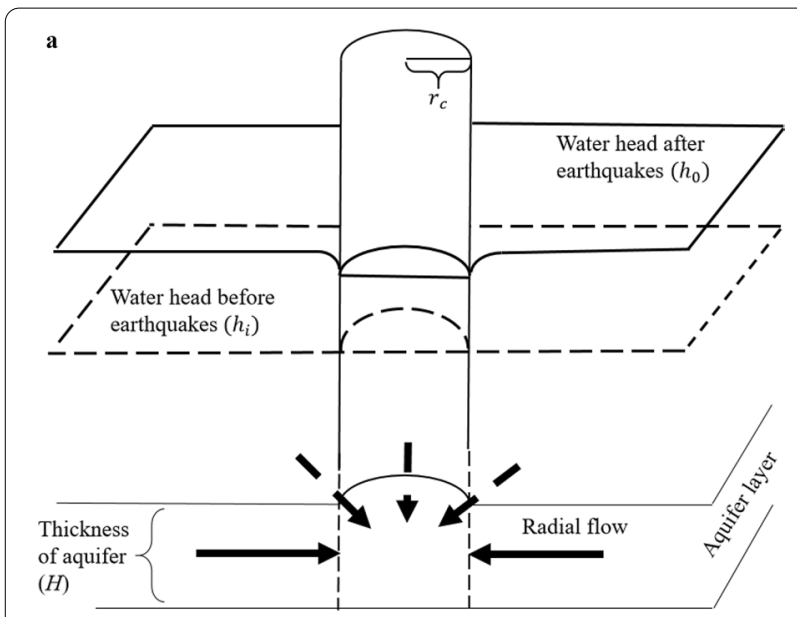

b

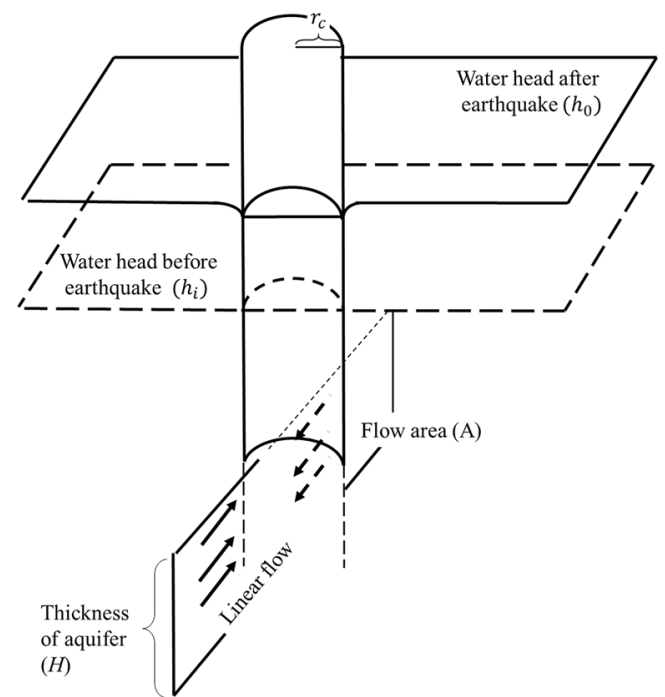

Fig. 6 Slug test model images. The images of slug test models for the radial flow case (a) and linear flow case (b). The arrows show the flow directions

radial flow was considered the groundwater that fluxes in a homogeneous medium. The linear flow can be imaged as groundwater flow into fractures.

In the case of radial flow, Cooper et al. (1967) and Karasaki et al. (1988) provided a solution for the change in the well water level in a slug test as follows:

$$
\begin{aligned}
& h_{s}\left(t_{s}\right)=\frac{4 \omega}{\pi^{2}} \int_{0}^{\infty} e^{-t_{s} \mu^{2} / \omega} \frac{d \mu}{\mu\left[\Phi^{2}(\mu)+\Psi^{2}(\mu)\right]}, \\
& h_{s}=\left(h-h_{i}\right) /\left(h_{0}-h_{i}\right),
\end{aligned}
$$

$$
\begin{aligned}
& t_{s}=\frac{2 \pi k H t}{\pi r_{c}^{2}}, \\
& \omega=\frac{2 \pi r_{s}^{2} S_{s} H}{\pi r_{c}^{2}}, \\
& \Phi(\mu)=\mu J_{0}(\mu)-\omega J_{1}(\mu), \\
& \Psi(\mu)=\mu Y_{0}(\mu)-\omega Y_{1}(\mu),
\end{aligned}
$$

where $h$ is the hydraulic head, $h_{i}$ is the initial groundwater level in the well; $h_{0}$ is the final groundwater level change, $k$ is the hydraulic conductivity of the formation; $S_{s}$ is the specific storage of the formation; $r_{s}$ is the radius of the screen part of the borehole; $r_{c}$ is the radius of the casing part of the borehole; $J_{0}$ is Bessel function of the first kind, zeroth order; $J_{1}$ is Bessel function of the first kind, first order; $Y_{0}$ is Bessel function of the second kind, zeroth order; $Y_{1}$ is Bessel function of the second kind, first order; and $H$ is the thickness of the aquifer.

For linear flow, the change in the well groundwater level is expressed by Karasaki et al. (1988) as follows:

$$
\begin{aligned}
& h_{s}\left(t_{s}^{\prime}\right)=e^{\omega t_{s}^{\prime}} \operatorname{erfc}\left(\omega t_{s}^{\prime}\right)^{\frac{1}{2}}, \\
& h_{s}=\frac{h-h_{i}}{h_{0}-h_{i}}, \\
& t_{s}^{\prime}=\frac{k A t}{r_{s} \pi r_{c}^{2}}, \\
& \omega=\frac{A r_{S} S_{s}}{\pi r_{c}^{2}},
\end{aligned}
$$

where $A$ is the area open to flow.

In the aforementioned equations, $t_{s}$ and $t_{s}^{\prime}$ are dimensionless time defined by Eqs. (6) and (12), respectively. The parameter $\omega$, the storage ratio of the formation to well, was determined by the specific storage of the aquifer. The time constants of groundwater level changes were configured by hydraulic conductivity and the specific storage of the aquifer.

\section{Results}

To compute solutions (4) and (10) of groundwater level change for the slug test model, the specific storage is necessary. As no data for the specific storage of the Oi well is available, we calculated the specific storage from the barometric efficiency. According to Wang (2000), 
the specific storage can be calculated by the following equation:

$$
S_{s}=\frac{\phi}{K_{f} B}
$$

where $\phi$ is porosity, $K_{f}$ is fluid bulk modulus and $B$ is the barometric efficiency. The geologic formation of the target aquifer of the Oi well is tuff-breccia (Yokoyama et al. 1995). On the basis of the physical properties of rock database, PROCK (Murata et al. 1991), the porosity of tuff-breccia is ranging from 1 to $40 \%$. This porosity range is assumed for the estimation of the specific storage. Water bulk modulus $\left(K_{f}\right)$ is valued $2.2 \mathrm{GPa}$. Under this assumption, the specific storage of the Oi well ranges from $1.2 \times 10^{-7}$ to $4.7 \times 10^{-6} \mathrm{~m}^{-1}$, which is considered to be an uncertainty of the specific storage of the Oi well in this study.

We first calculated the radial flow case from Eqs. (4) to (9) with the hydraulic conductivity of $5.5 \times 10^{-6}$ $\mathrm{m} / \mathrm{s}$ as listed in Table 1 . The results are presented in Fig. $7 \mathrm{a}$ with the observed data, which were normalized by Eq. (5). The initial groundwater level $\left(h_{i}\right)$ is determined by eye. The final water level $\left(h_{0}\right)$ was defined by the groundwater level $1 \mathrm{~h}$ after the beginning of the increase.

The red and orange lines in Fig. 7a correspond to the results with the specific storages of $1.2 \times 10^{-7}$ and $4.7 \times 10^{-6} \mathrm{~m}^{-1}$, respectively. The shapes of these theoretical curves are very similar to the observed data, suggesting the application of the slug test model for the radial flow case is suitable. However, the area bounded by these lines located just below the observed data, suggests that the time constants of the theoretical curves are shorter than those of the observation. The purple line in Fig. $7 \mathrm{a}$ indicates $1 / e$ of $h_{s}$, showing that the time at the intersection with the groundwater level curve is a time constant. The measurements of hydraulic conductivity usually contain errors. Takeuchi et al. (2007) reported that repeated measurements of hydraulic conductivity resulted in values in the range of nearly one order. Hence, we search for the value of hydraulic conductivity, by which the theoretical curves locate just above the observed data. This value is found to be approximately $2.0 \times 10^{-6} \mathrm{~m} / \mathrm{s}$. The theoretical curves are demonstrated in Fig. $7 \mathrm{a}$.

As shown in Fig. 7a, the observed data are bounded by the theoretical curves which were calculated from the hydraulic conductivity $2.0 \times 10^{-6}$ and $5.5 \times 10^{-6} \mathrm{~m} / \mathrm{s}$. In consideration of the measurement error of hydraulic conductivity in the field experiments (Takeuchi et al. 2007), the difference of $2.0 \times 10^{-6}$ and $5.5 \times 10^{-6} \mathrm{~m} / \mathrm{s}$ is within the uncertainty of the field experiments. The uncertainty of the hydraulic conductivity measurements probably comes from the difference of area which is affected by the groundwater flow. The results indicate the radial flow case of the slug test model was consistent with the observation.

Figure $7 \mathrm{~b}$ shows the results of the linear flow case of the slug test model with observed groundwater level data, which were normalized in the same manner as those in Fig. 7a. The theoretical groundwater level change was calculated using Eqs. (10)-(13), in which we assume the values for the flow area, $A$ (Fig. $6 \mathrm{~b}$ ). We use the same values of the specific storage applied in the radial flow case.

We attempted to search for the proper value of $A$ as shown in Fig. 7b. We calculated the theoretical groundwater level changes are for the flow area $A$ from 1 to $1000 \mathrm{~m}^{2}$. The red and green lines correspond to the results with the specific storages of $1.2 \times 10^{-7}$ and $4.7 \times 10^{-6} \mathrm{~m}^{-1}$, respectively. The blue line indicates $1 / e$ of $h_{s}$ in the same manner as in Fig. 7a. The observed curves are bounded by the theoretical curves with 100$1000 \mathrm{~m}^{2}$ in $A$. However, the shapes of these theoretical curves are far different from the observed, indicating that the linear flow case does not satisfy the observation. Hence, the linear flow model was not suitable for applying the observed sustained change.

The aforementioned results of the two flow model types indicate that the radial flow case of the slug test model adequately represents the observed sustained groundwater level increase triggered by the earthquake in the Oi well and that the radial flow case was preferable to the linear flow case. The success of the application of the slug test model indicates occurrence of a sudden increase in the pore-pressure of the aquifer surrounding the well. This is because the theoretical curve of the slug test shows the groundwater level response in a well is due to an abrupt change in the pressure difference between the well and the neighboring aquifer. The theoretical curves of the possible values cover the observed data, and the theoretical curves represent the response to a steplike change in the pore-pressure. Thus, the buildup time of the sudden increase was approximately $100-500 \mathrm{~s}$, comparable to the range of the observed time constants, i.e., 156-363 s. We emphasize that hydraulic conductivity measured at the time of well construction (Table 1) can reproduce exponential decay curves using the slug test model of the radial flow case suitable to the observed data.

In the previous section, we found that the observed sustained ground water level is well approximated by the decaying exponential function. Here, we also applied the decaying exponential, error, and logistic functions to the solution of radial flow (Eq. (4)), and found the decaying 

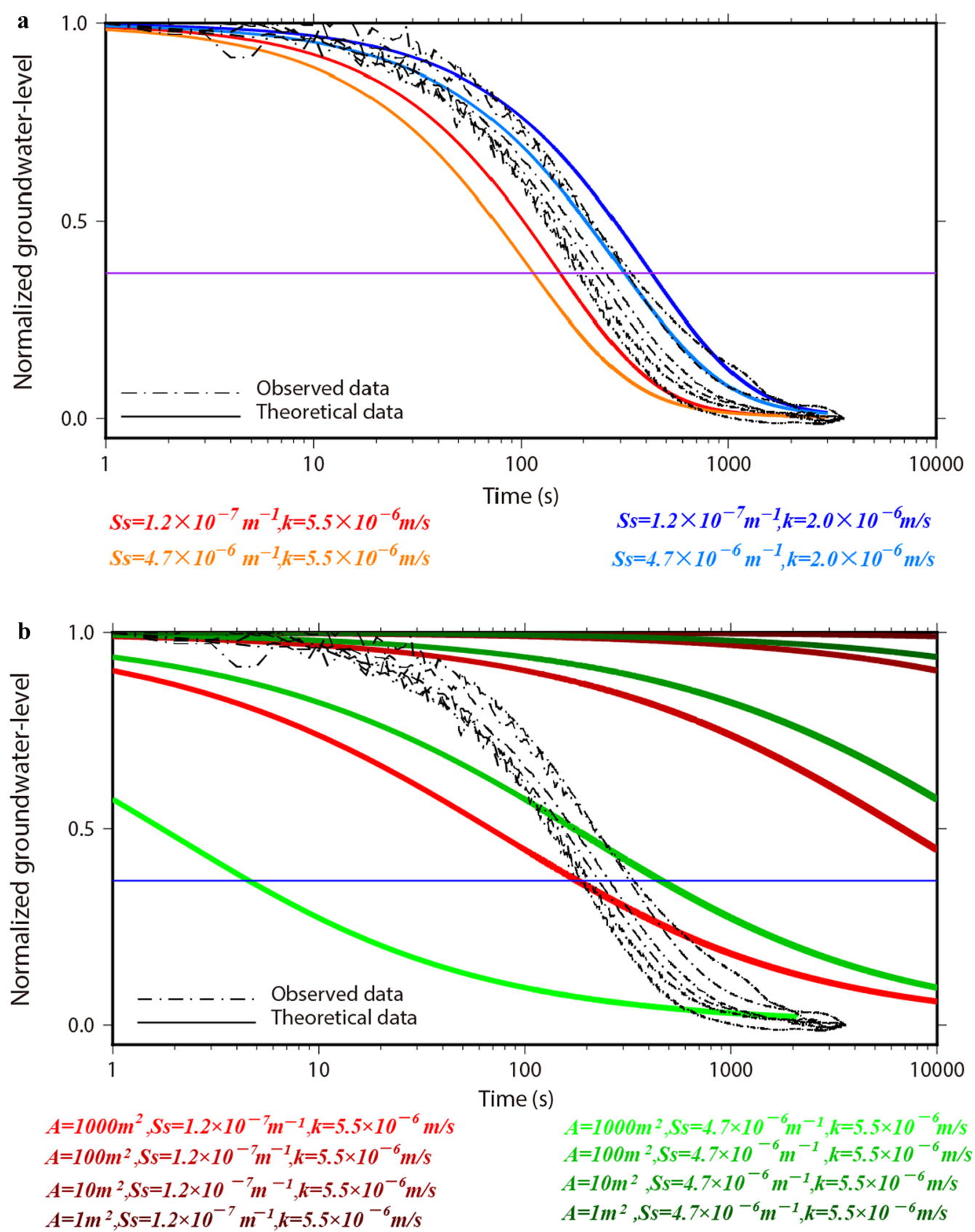

Fig. 7 Slug test model results. a Results of the slug test model for the radial flow case. The one-dot chain lines show the observed data for the target events. The colored solid lines show the theoretical curves which were calculated using Eqs. (4)-(9). The horizontal axis is logarithmic time. The vertical axis is the normalized groundwater level $\left(h_{s}\right.$ in Eq. (5)). The purple line indicates $1 /$ e of $h_{s}$, showing that the time at the intersection with the groundwater is a time constant. b Results of the slug test model for the linear flow case. The one-dot chain lines show the observed data. The colored solid lines show the theoretical curves which were calculated using Eqs. (10)-(13). The horizontal axis is logarithmic time. The vertical axis is the normalized groundwater level ( $h_{s}$ in Eq. (5)). The purple line is the same as a

exponential function is the best fit function among the three. The agreement supports that the slug test model of radial flow represents the observed coseismic sustained increase of groundwater level. The time constant of the slug test model is controlled by the hydraulic conductivity of well-aquifer system, therefore, this model explains the reason why the observed time constant is independent of the magnitudes or intensities of earthquakes. 


\section{Discussion}

We categorized the coseismic groundwater level changes observed by the HSRI groundwater level observational network into three types. The first type is the sustained groundwater level increase observed at the Oi well, the second is the groundwater level decrease appearing immediately after the 2011 earthquake off the Pacific Coast of Tohoku (event 1 ) at several wells and the third is the oscillatory groundwater level change observed by all the wells of the HSRI observational network. Regarding the first type, the theoretical response based on the slug test model can explain the observation.

At the time of the 2011 earthquake off the Pacific Coast of Tohoku (event 1), the groundwater level decreased by $25 \mathrm{~cm}$ at the Oi well (the second type), several times greater than the groundwater level increase of the first type. The decay time constant was approximately $200 \mathrm{~s}$ as shown in Fig. 2d. The time constant was comparable to that of the sustained increase responses (first type) observed in the Oi well (Table 3 ). The groundwater level decreased not only at the Oi well but also at the Ninomiya well (by more than $50 \mathrm{~cm}$ ) and at the Minamiashigara well (approximately $30 \mathrm{~cm}$ ) as shown in Fig. 2d.

The coefficient of the groundwater level response to volumetric strain is evaluated to be $5 \times 10^{5} \mathrm{~m} /$ strain for the semidiurnal earth tides from the observed groundwater level changes at the Oi well and the earth tide calculated by GOTIC2 (Matsumoto et al. 2001). This response predicts approximately $40 \mathrm{~cm}$ groundwater level decrease at the Oi well by the volumetric strain due to the event $1\left(8.7 \times 10^{-7}\right.$ strain) calculated from the computer program of Okada (1992) and the CMT solutions by GCMT project (https://www.globalcmt.org/). Taking account of the difference between the characteristic period of the earthquake and those of the earth tides, the observed groundwater level decrease of $25 \mathrm{~cm}$ is in harmony with the predicted value from the response to the earth tide. This agreement supports the consideration that the groundwater level decrease due to event 1 was caused by the sudden static extensional strain generated by fault dislocation.

As Roeloffs (1996) pointed out, the pore-pressure changed simultaneously with the volumetric strain, and consequently the coseismic strain would be expected to produce step-like or sudden water level changes. This process causes the groundwater flow from the well to aquifer. The flow is in an opposite direction of the slug test model that we applied to the first type water level change at the Oi well, but is induced by the step-like pore-pressure changes between the pressure inside the well and the pore-pressure outside of the well in the same manner as the slug test model. The decay time constant for event 1 is considered to represent a time constant of the well-aquifer system responding to the step-like change of the pressure difference between inside and outside of the well. The time constants for the first type are comparable to that for event 1 . This agreement supports our implication that the sustained increase at the Oi well is a response to the step-like pore-pressure change outside of the well as inferred from the slug test model.

A sustained increase response (the first type) was uniquely observed at the Oi well in the HSRI groundwater level observational network. The successful application of the slug test model to represent the time series of the groundwater response indicates that the sustained increases in groundwater level are likely caused by the sudden increase in the pore-pressure of the aquifer surrounding the well by earthquakes. Till now, there have been many reports regarding the coseismic sustained groundwater level changes, and several mechanisms have been proposed to explain them (e.g., Roeloffs 1996, 1998; Brodsky et al. 2003; Wang and Manga 2010, 2014). The mechanisms are principally classified into two regimes, one is due to static strain, and the other is due to dynamic strain by earthquakes. Here, we first consider the possibility of the poroelastic static strain, and then we examine and discuss the mechanisms due to dynamic strain.

Poroelastic static strain produces both positive (increase) and negative (decrease) changes depending on the geometric relation between a fault dislocation and a well. The groundwater level changes at the Oi well are always positive and are independent of hypocenter locations. To produce groundwater increase greater than $5 \mathrm{~cm}$, volumetric strain greater than at least $10^{-8}$ is necessary, if we adopt the sensitivity coefficient of water head response to volumetric strain, $5 \times 10^{6} \mathrm{~m}$, by Roeloffs (1996). By estimating static strain at the Oi well for the events in Table 2, the estimations of absolute volumetric strain change are smaller than $4 \times 10^{-9}$ for all events except for event 1 , using the computer program of Okada (1992) and the CMT solutions by GCMT project (https:// www.globalcmt.org/). Seven of the 11 events indicate extensional volumetric strain, which should cause the groundwater level decrease.

Not only the estimated volumetric strains were too small to cause the groundwater level changes greater than $5 \mathrm{~cm}$, but also their signs of the seven events suggest the opposite groundwater level change. Therefore, we conclude that the poroelastic static strain following an earthquake does not adequately explain the sustained increase at the Oi well.

Next, we consider the effect of the dynamic strain by seismic waves on the aquifer. First, we examine the model in which dynamic strain by seismic waves creates a pressure source located away from the well that 
causes sustained changes in groundwater levels. Roeloffs (1998) proposed a model in which changes in water level are caused by a flow rate change due to local pressure increases at some distance from the well. At the Oi well, the observed time constant ranged from 156 to $363 \mathrm{~s}$. These observed time constants include the time range for the pore-pressure to be transmitted from the pressure source to the aquifer outside the well, and the time range for pore-pressure outside the well to be transmitted into the well changing the groundwater level. The latter time constant calculated by the slug test model is the minimum time constant, since it is the response time required for groundwater to flow in from the immediate vicinity of the well.

We calculated the distance from the pressure source to the well, based on the time constant observed at the $\mathrm{Oi}$ well, assuming the one-dimensional flow in porous media using the equation described Bear and Cheng (2010), $h(x, t)=1-\operatorname{erf}\left(x / \sqrt{4 k t / S_{s}}\right)$. In this equation, $h$ is normalized head, $x$ is the distance from localized pressure source to the well, $k$ is the hydraulic conductivity, $S_{s}$ is the specific storage and $t$ is the time. In the calculation, we use the hydraulic conductivity of $5.5 \times 10^{-6} \mathrm{~m} / \mathrm{s}$, and the specific storage of $1.2 \times 10^{-7} \mathrm{~m}^{-1}$ and $4.7 \times 10^{-6} \mathrm{~m}^{-1}$, which are obtained in "Results" for the Oi well. The characteristic lengths corresponding to the minimum buildup time, $156 \mathrm{~s}$ are 60 and $9 \mathrm{~m}$, corresponding to the specific storage of $1.2 \times 10^{-7} \mathrm{~m}^{-1}$ and $4.7 \times 10^{-6} \mathrm{~m}^{-1}$, respectively. These distances show that the source of pore-pressure increase should be within at most $60 \mathrm{~m}$, since the time for the pressure outside the well to be transmitted into the well is neglected, and the pressure increase at the source is step-like in this calculation. Considering the time constant due to the well-aquifer response ranging from 100 to $500 \mathrm{~s}$ which is calculated from the slug test model, it is unable to distinguish whether the well is inside the pressure source or immediately close to the pressure source from the observed groundwater level data. However, it is certain that the sustained groundwater level increase was caused by the sudden pore-pressure increase due to the dynamic strain.

Here, we qualitatively examine the cases where seismic wave oscillation may cause sudden pore-pressure changes of the aquifer surrounding the Oi well. We consider three mechanisms for the sudden increase of porepressure caused by the dynamic strain of seismic waves as the candidates for the sustained groundwater level increase: (a) permeability change due to barrier removal on the fracture surface, (b) undrained consolidation, and (c) gas bubble nucleation and growth.

(a) Permeability change due to barrier removal on the fracture surface.
Brodsky et al. (2003) proposed a model in which the permeability of the fractures around the well changed by removing the barriers during the clogging and unclogging cycle caused by seismic waves. This model can produce a step-like pore-pressure change in the aquifer, and can be applied to both water level drop and rise, depending on the locations of the well and the barrier. However, in applying this model to the Oi well case, there are two difficulties. One is the buildup time that depends on the distribution of the barriers, which may consist of deposits in the aquifer, and may vary case by case. In contrast to the expectation, the buildup times at the Oi well are almost constant. The other difficulty is a response to the successive earthquakes, where no or less step is expected to the second earthquake as described by Brodsky et al. (2003). In the Oi well case, for event 2, comparable water level changes were observed at the successive earthquakes of Mw4.9 and Mw5.4 with an interval of $3 \mathrm{~min}$ as shown in Fig. 4.

(b) Undrained consolidation.

Undrained consolidation is a well-known mechanism for liquefaction in an unconfined aquifer in soil layer (e.g., Ishihara 1996; Wang and Manga 2014). Stewart and Knox (1995) discusses that the possible maximum depth of liquefaction reaches $300-\mathrm{m}$ depth on the basis of the laboratory studies for soil. For porous media, Biot (1941) described the basic equations for general cases of consolidation. This theory predicts that volume reduction of porous media by the skeleton structure change causes pore-pressure increase. Successive volume reduction of the aquifer by the skeleton structure change can cause the successive pore-pressure increases with small interval time such as in the case of event 2. The aquifer depth of the Oi well is $300 \mathrm{~m}$ but the aquifer layer at the Oi well is the quaternary tuff-breccia, not the soil. It is necessary to examine whether the same behavior occurs in the Oi well in future experimental study or observation. In present study, we consider that the consolidation is one of the possible mechanisms for the groundwater level increase at the Oi well.

(c) Gas bubble nucleation and growth.

The effect of gas bubble was another possibility explaining the sustained groundwater level change in the well (Brodsky et al. 1998; Matsumoto and Roeloffs 2003; Crews and Cooper 2014a, b). Crews and Cooper (2014b) show the possibility of a groundwater level increase resulting from $\mathrm{CO}_{2}$ gas bubble nucleation and growth on the basis of a laboratory experimental study. The experiment by Crews and Cooper (2014b) indicates that the pore-pressure builds up during several cycles of the confining pressure oscillation, and therefore, the gas bubble nucleation and growth can explain the coseismic sudden pore-pressure increase. 
Occurrence of $\mathrm{CO}_{2}$ gas bubble nucleation and growth due to an oscillation in dynamic stress requires sufficient $\mathrm{CO}_{2}$ content in the pore water, that is, a saturated or subsaturated condition. Although there were no reports of detecting $\mathrm{CO}_{2}$ bubbles during the construction of the $\mathrm{Oi}$ well, high $\mathrm{CO}_{2}$ content was reported across the KozuMatsuda fault (Earthquake Prediction and Geochemistry Research Group, GSJ 1984), at the vicinity of which the Oi well is located (Fig. 1). As higher $\mathrm{CO}_{2}$ contents have often been reported along active faults (e.g., Kerrick 2001), and the Kozu-Matsuda fault is an active fault between the Philippine Sea plate and the North American plate, high $\mathrm{CO}_{2}$ content is expected in the water of the aquifer at the Oi well. To judge the possibility of the gas bubble nucleation and growth for the mechanism of the groundwater level increase at the Oi well, the measurements of the gas content in the water of the well is a key observation.

Aforementioned qualitative examination of the possible mechanisms suggests that the cause of the earthquaketriggered pore-pressure increase around the Oi well is not definitive. More research is necessarily to specify the cause of sudden pore-pressure change in the aquifer by earthquakes.

\section{Conclusions}

Three types of coseismic groundwater level changes were observed in six wells belonging to the HSRI groundwater observational network in the western part of the Kanagawa prefecture, central Japan. A total of 12 coseismic events were extracted from the observed data from 2011 to 2016. The observation responses were classified into three types. The first type was the sustained increase response uniquely observed at the Oi well. The second type was the decrease in the groundwater level appearing only after the 2011 earthquake off the Pacific Coast of Tohoku. This type of response was not only observed in the Oi well but also observed clearly in two other wells. The third type was the oscillatory response to an earthquake, which appeared in all the wells of the groundwater level monitoring system. In this study, we addressed the first type of response at the Oi well.

We applied decaying exponential, error, and logistic functions to approximate the first type coseismic groundwater level change. Among the three functions, the decaying exponential function best matched the time series observed at the Oi well for 10 of the 11 first type events. The time constants of 11 events ranged from 156 to $363 \mathrm{~s}$, averaging $254 \mathrm{~s}$, and its standard deviation was $58 \mathrm{~s}$.

During the second step, we applied the slug test model to the sustained increase in the Oi well and found that the hydraulic conductivity around the Oi well satisfied the observed time series, indicating the occurrence of a sudden pore-pressure increase around the well. The cause of the sudden pore-pressure increase around the Oi well, triggered by earthquakes, is not definitive, but the mechanisms that directly increase pore-pressure in the aquifer around the well are preferable to mechanisms that increase flow rate in the aquifer.

We examined several candidates for the cause of the coseismic pore-pressure increase around the Oi well. We found that the poroelastic static strain change due to earthquake is not suitable for the sustained groundwater level increase for the Oi well case. Qualitative examination suggests that following three models possibly explain the observed buildup times at the $\mathrm{Oi}$ well, but are not definitive: (a) permeability change due to barrier removal on the fracture surface, (b) undrained consolidation, and (c) gas bubble nucleation and growth. More research is necessary to specify the cause and mechanism for the coseismic sustained groundwater level increase at the Oi well.

\section{Abbreviation}

HSRI: The Hot Spring Research Institute of Kanagawa Prefecture.

\section{Acknowledgements \\ We would like to thank to D. Asahina, T. Takemura, S. Takeuchi, T. Tokunaga, M. Murase, and K. Goto for their discussions and encouragements. We would also like to thank J. M. Lees and Y. Okada for his helpful suggestion. We would like to thank anonymous reviewers and Wojciech Debski for their helpful comments, which greatly improved this manuscript. Generic Mapping Tools (Wessel and Smith 1998) was used to draw the figures.}

\section{Authors' contributions}

YL and MU analyzed the data, built the model and participated in the sequence alignment and drafted the manuscript. $\mathrm{KI}$ and $\mathrm{MH}$ observed and recorded the groundwater level and helped in building the model used in this study. All the authors read and approved the final manuscript.

\section{Funding}

Not particularly.

\section{Availability of data and materials}

The groundwater level data are supported by the Hot Spring Research Institute of Kanagawa Prefecture. The seismometer data are download from the National Research Institute for Earth Science and Disaster Resilience. http:// www.fnet.bosai.go.jp/top.php?LANG=ja.

\section{Declarations}

Ethics approval and consent to participate

Not applicable.

\section{Consent for publication}

Not applicable.

\section{Competing interests}

The authors declare that they have no competing interests.

\section{Author details}

${ }^{1}$ Advanced Industrial Science and Technology, Earthquake and Volcano Geology, Central 7, Higashi 1-1-1, Tsukuba, Ibaraki 305-8567, Japan. ${ }^{2}$ Hot Springs Research Institute of Kanagawa Prefecture, 586 Iryuda, Odawara, Kanagawa, 
Japan. ${ }^{3}$ Department of Earth and Environmental Sciences, College of Humanities and Sciences, Nihon University, 3-25-40 Sakurajosui, Setagaya-ku, Tokyo, Japan.

Received: 9 October 2020 Accepted: 4 August 2021 Published online: 25 August 2021

\section{References}

Abramowitz M, Stegun IA (1972) Handbook of mathematical functions with formulas, graphs, and mathematical tables, tenth. U.S. Goverment Printing Office, Washington

Akaike H (1987) Factor analysis and AIC. Psychometrika 52:317-332. https:// doi.org/10.1007/BF02294359

Bear J, Cheng AD (2010) Modeling groundwater flow and contaminant transport. Springer, Berlin

Biot MA (1941) General theory of three-dimensional consolidation. J Appl Phys 12:155-164

Brodsky EE, Roeloffs E, Woodcock D, Gall I, Manga M (2003) A mechanism for sustained groundwater pressure changes induced by distant earthquakes. J Geophys Res 108:1-10. https://doi.org/10.1029/2002jb002321

Brodsky EE, Sturtevant B, Kanamori H (1998) Earthquakes, volcanoes, and rectified diffusion. J Geophys Res 103:23827-23838

Cooper HH, Bredehoeft D, Papadopulos S, Bennett R (1965) The response of well-aquifer systems to seismic waves. J Geophys Res. 70:3915-3926

Cooper HHJ, Bredehoeft JD, Papadopulos IS (1967) Response of a finite-diameter well to an instantaneous charge of water. Water Resour Res 3:263-269

Crews JB, Cooper CA (2014a) Transient pore pressure response to confining stress excursions in Berea sandstone flooded with an aqueous solution of CO 2. Water Resour Res 50:4775-4786. https://doi.org/10.1002/2014W R015305

Crews JB, Cooper CA (2014b) Experimental evidence for seismically initiated gas bubble nucleation and growth in groundwater as a mechanism for coseismic borehole water level rise and remotely triggered seismicity. J Geophys Res Solid Earth 119:7079-7091. https://doi.org/10.1002/2014J B011398

Crotwell HP, Owens TJ, Ritsema J (1999) The TauP Toolkit: flexible seismic traveltime and raypath utilities. Seis Res Letters 70:154-170

Earthquake Prediction and Geochemistry Research Group, GSJ (1984) Outline of earthquake prediction research using groundwater and underground gas by the Geological Survey of Japan (part3). Chishitsu News 359:16-26 (in Japanese)

Feng M, An M (2010) Lithospheric structure of the Chinese mainland determined from joint inversion of regional and teleseismic Rayleigh-wave group velocities. J Geophys Res Solid Earth 115:1-16. https://doi.org/10, 1029/2008JB005787

Hantush MS (1964) Drawdown around wells of variable discharge. J Geophys Res 69:4221-4235

Ishihara K (1996) Soil behaviour in earthquake geotechnics. Oxford University Press Inc., New York

Itadera K (2003) A simple method of correcting groundwater level observation data and thresholds for determining anomalies. Bull Hot Springs Res Inst Kanagawa Prefect 35(47-52):2003 (in Japanese)

Karasaki K, Long JCS, Witherspoon PA (1988) Analytical models of slug tests. Water Resour Res 24:115-126. https://doi.org/10.1029/WR024i001 p00115

Kerrick DM (2001) Present and past nonanthropogenic CO2 degassing from the solid earth. Rev Geophys 39:565-585. https://doi.org/10.1029/2001R G000105

Kinoshita C, Kano Y, Ito H (2015) Shallow crustal permeability enhancement in central Japan due to the 2011 Tohoku earthquake. Geophys Res Lett 42:773-780. https://doi.org/10.1002/2014GL062792

Kipp KJ (1985) Type curve analysis of inertial effects in the response of a well to a slug test. Water Resour Res 21:1397-1408

Kitagawa Y, Koizumi N (2011) Changes in groundwater levels, groundwater pressures and discharge rates a day after the 2011 Off the Pacific Coast of Tohoku Earthquake ( M9. 0). Active Fault Paleoearthq Res 11:309-318 (in Japanese with English abstract)

Koizumi N, Kinoshita C (2016) Postseismic well water level increases at the Dogo Hot Spring in Japan. Bull Seismol Soc Jpn 70:125-134. https://doi, org/10.4294/zisin.2016 (in Japanese with English abstract)
Koizumi N, Kano Y, Kitagawa Y, Sato T, Takahashi M, Nishimura S, Nishida R (1996) Groundwater anomalies associated with the 1995 Hyogo-ken Nanbu Earthquake. J Phys Earth 44:373-380

Kühn M, Schöne T (2018) Investigation of the influence of earthquakes on the water level in the geothermal reservoir of Waiwera (New Zealand). Adv Geosci 45:235-241. https://doi.org/10.5194/adgeo-45-235-2018

Lai G, Jiang C, Han L, Sheng S, Ma Y (2016) Co-seismic water level changes in response to multiple large earthquakes at the LGH well in Sichuan, China. Tectonophysics 679:211-217. https://doi.org/10.1016/j.tecto.2016.04.047

Liu L-B, Roeloffs E, Zheng X-Y (1989) Seismically induced water level fluctuations in the Wali Well, Beijing, China. J Geophys Res 94:9453-9462

Matsumoto K, Sato T, Takanezawa T, Ooe M (2001) GOTIC2: A program for computation of oceanic tidal loading effect. J Geod Soc Jpn. 47:243-248. https://doi.org/10.11366/sokuchi1954.47.243

Matsumoto N, Roeloffs EA (2003) Hydrological response to earthquakes in the Haibara well, central Japan - II. Possible mechanism inferred from timevarying hydraulic properties. Geophys J Int 155:899-913. https://doi.org/ 10.1111/j.1365-246X.2003.02104.X

Murata Y, Suda Y, Kikuchi T (1991) Rock physical properties of Japan-density, magnetism, P-wave velocity, porosity, thermal conductivity, Geological Survey of Japan Report, No. 276. (in Japanese)

National Research Institute for Earth Science and Disaster Resilience (2019) NIED F-net National Research Institute for Earth Science and Disaster Resilience, doi: https://doi.org/10.17598/NIED.0005

Niwa M, Takeuchi R, Onoe H, Tsuyuguchi K, Asamori K, Umeda K, Sugihara K (2012) Groundwater pressure changes in central japan induced by the 2011 off the pacific coast of Tohoku earthquake. Geochemi Geophys Geosyst 13:1-15. https://doi.org/10.1029/2012GC004052

Ohzono M, Yabe Y, linuma T, Ohta Y, Miura S, Tachibana K, Sato T, Demach T (2012) Strain anomalies induced by the 2011 Tohoku earthquake (mw 9.0) as observed by a dense gps network in northeastern japan. Earth Planets Space 64:1231-1238. https://doi.org/10.5047/eps.2012.05.015

Okada Y (1992) Internal deformation due to shear and tensile faults in a halfspace. Bull Seismol Soc Am 82:1018-1040

Okada Y, Kasahara K, Hori S, Obara K, Sekiguchi S, Fujiwara H, Yamamoto A (2004) Recent progress of seismic observation networks in Japan - Hinet, F-net, K-NET and KiK-net- . Earth Planets Space. 56:BF03353076. https://doi.org/10.1186/BF03353076

Papadopulos SS, Bredehoeft JD, Cooper HH (1973) On the analysis of 'slug test' data. Water Resour Res 9:1087-1089. https://doi.org/10.1029/WR009 i004p01087

Roeloffs EA (1996) Poroelastic techniques in the study of earthquake-related hydrologic phenomena. Adv Geophys 37:135-195

Roeloffs EA (1998) Persistent water level changes in a well near Parkfield, California, due to local and distant earthquakes. J Geophys Res Solid Earth 103:869-889

Roeloffs EA, Danskin WR, Farrar CD, Galloway DL, Namlin SN, Quilty EG, Quinn HM, Schaefer DH, Sorey ML, Woodcock DE (1995) Hydrologic effects associated with the June 28, 1992 Landers, California, earthquake sequence. USGU Open File Report 95-42

Shi ZM, Wang GC, Liu CL, Mei J, Wang J, Fang H (2013) Coseismic response of groundwater level in the Three Gorges well network and its relationship to aquifer parameters. Chin Sci Bull 58:3080-3087. https://doi.org/10. 1007/s11434-013-5910-3

Stewart D, Knox R (1995) What is the Maximum Depth Liquefaction Can Occur? Third Int Conf Recent Adv Geotech Earthq Eng Soil Dyn. 27.

Takeuchi S, Nakano K, Hirata Y, Shinshi Y, Nishigaki M (2007) Methodology for reliablie hydrotesting with sequential testing technique in deep borehole. J Groundw Hydrol 49:17-32 (in japanese with english abstract)

Theis CV (1952) The relation between the lowering of the piezometric surface and the rate and duration of discharge of a well using ground water storage. U. S. Geological Survey Water Resources Division Ground Water Branch, Ground Water Notes Hydraulics No. 5.

Wang FH (2000) Theory of linear poroelasticity with applications to geomechanics and hydrogeolgy. Princeton University Press

Wang CY, Manga M (2010) Hydrologic responses to earthquakes and a general metric. Geofluids 10:206-216. https://doi.org/10.1111/j.1468-8123.2009. 00270.x

Wang C, Manga M (2014) Earthquake and water, encyclopedia of complexity and systems. Science. https://doi.org/10.1007/978-3-642-27737-5_606-1 
Wang CY, Chia Y, Wang PL, Dreger D (2009) Role of S waves and Love waves in coseismic permeability enhancement. Geophys Res Lett 36:1-5. https:// doi.org/10.1029/2009GL037330

Wessel P, Smith WH (1998) New, improved version of Generic Mapping Tools released. Eos Trans AGU 79:579

Yamazaki H (1993) The Kozu-Matsuda fault and its seismotectonic meaning in the Southern Kanto Japan. Jour Geogr 102:365-373 (in Japanese)

Yokoyama T, Odaka S, Itadera K, Nagase K, Sugiyama S (1995) Monitoring system and analysis of groundwater level for investigating the method to predict Wetern-Kanagawa Earthquake. Bull Hot Springs Res Inst Kanagawa Prefect 26:21-36 (in Japanese)
Zhang Y-Q, Liu C-M, Shen Y-J (2001) Analysis of the groundwater level changein Taihang Piedmont-a case study from Luancheng County. Chin J Eco-Agric 9:38-40 (in Chinese with English abstract)

\section{Publisher's Note}

Springer Nature remains neutral with regard to jurisdictional claims in published maps and institutional affiliations.

\section{Submit your manuscript to a SpringerOpen ${ }^{\circ}$ journal and benefit from:}

- Convenient online submission

- Rigorous peer review

- Open access: articles freely available online

- High visibility within the field

- Retaining the copyright to your article

Submit your next manuscript at $\boldsymbol{\nabla}$ springeropen.com 